\title{
The epidemiology of anencephaly and spina bifida in Izmir, Turkey, in the light of recent aetiological theories
}

\author{
M. R. BUCKLEY AND OKTAY ERTEN \\ From the Department of Obstetrics and Gynaecology, Ege University, Izmir, Turkey
}

SUMMARY The data from this study suggest that, in western Turkey, potato consumption and water hardness do not play a significant role in the aetiology of anencephaly and spina bifida (ASB). Several of the predictions of the fetus-fetus interaction theory are not supported. Other predictions could not be tested because of lack of information on the dizygotic (DZ) twinning rate. Twin data from this study, together with previous material containing explicit information on zygosity, suggest that true concordance of a particular neural tube anomaly occurs only in monozygotic (MZ) twins. It also seems that even ASB concordance occurs in DZ twins only at a rate comparable with recurrence in siblings. This confirms the earlier refutation (Field and Kerr, 1974) of theo supposition of Nance (1971) that MZ twin pairs are strikingly discordant for ASB compared with DZ pairs. However, the evidence seems to go further than Field's assertion that MZ and DZ pairs are affected about equally. Concordance in DZ twins is in comparison with sibling data, but MZ pairs show a significantly higher rate of concordance in both categories. Finally, the incidence of ASB in Izmir compared with the areas of ethnic origin of the Turks, and the high representation of families from Balkan areas where the incidence more closely resembles that of Izmir, suggest that the genetic factor is important in this area.

Differences in the species prevent the application to human teratology of conclusions from animal experiments. For this reason, epidemiological studies, both wide-ranging and in small areas, are the main source of information in the search for an understanding of the aetiology of birth defects (British Medical Journal, 1976). The study of malformations of the central nervous system has been conducted in many parts of the world. However, apart from one study (Damyanov and Dutz, 1971), information from the Near East has been inadequate. This survey was carried out in order to help make up the deficiency and at the same time to test some recent theories in a fresh area.

\section{Material and methods}

A three-year survey was planned to cover all hospital births in Izmir, Turkey's third largest city (population 650000 ). The proportion of hospital confinements, based on a $40 \%$ sample of the city population, rose from $75 \%$ to $80 \%$ during the years of the survey. In addition, a fair proportion of complicated pregnancies, including anencephaly among the premature deliveries, occur in women from the surrounding villages and towns, and also terminate in the city hospitals, especially the university and state hospitals.

The co-operation of labour ward staffs and the regular checking of hospital records ensured that the data given here are complete and accurate. The only questionable point was the recording of spina bifida in the early part of 1974 , when some cases may have been lost. The mothers of ASB infants were interviewed before discharge, or recalled for discussion later in the survey. Particular attention was given to any factors that were likely to be relevant to aetiology according to previous studies.

When it was not possible to examine the infants, medical staff were questioned to confirm proper identification. If anencephaly occurred with spina bifida in the same infant, it was classified as anencephaly. Live births and stillbirths resulting from pregnancies of more than 28 weeks' duration were included. 


\section{Results}

\section{Incidence}

The incidence of ASB for the three years 1974-76 in the Izmir area is recorded in Table 1. If the incidence of spina bifida is adjusted to eliminate the doubtful 1974 record, a figure of 0.71 per 1000 is obtained.

\section{Seasonal and secular variation}

Fig. 1 shows the average monthly incidence over the three years. The incidence was higher in the winter and spring months. The known or estimated month of conception would indicate that the months when adverse aetiological factors may have been operating would be March to September. These months are the period of maximum hours of daylight, a correlation suggested by Record and McKeown (1961).

\section{Geographic-ethnic factors}

Of 107 patients from whom information was obtained, less than half (51) were born in the Izmir area. Another 46 were born in other parts of Turkey (western, 18; central, 18; eastern, 10), but it was

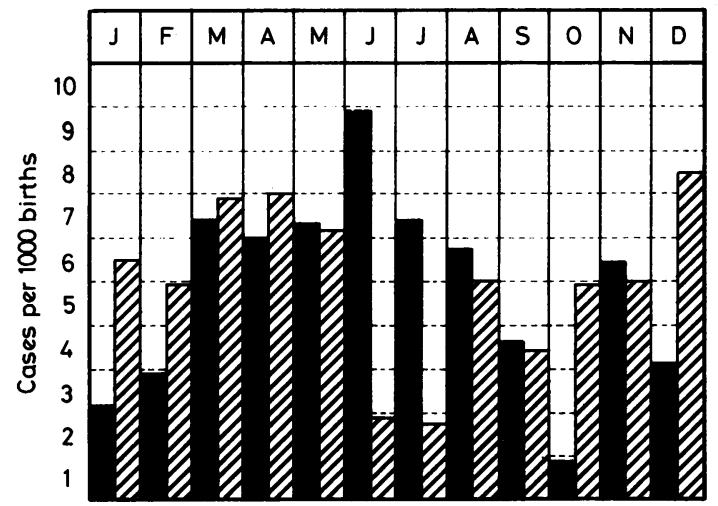

Fig. 1 Neural tube defects according to month of birth and estimated month of conception, Izmir, 1974-76. noteworthy that 10 were immigrants, eight from Yugoslavia and two from Bulgaria. They represent scattered communities in western Turkey descended from those who returned from the Ottoman Empire. This figure of nearly $10 \%$ is disproportionate to the size of the immigrant population in the area. However, in addition to the immigrant mothers, there were three more patients with immigrant husbands (from Greece, Albania, and Yugoslavia), and two with parents from Bulgaria and Yugoslavia. Altogether, more than $14 \%$ of patients had immigrant connections.

\section{Twins}

Anencephaly occurred in two twin pregnancies. The first were heterosexed twins. This patient had an elder sister who had had two sets of identical twins. In this pairing the female was anencephalic and the male was normal. The four previous pregnancies of the patient had resulted in normal female infants.

The second twin pair were monoamniotic males, one spina bifida and one anencephaly. This was a first pregnancy in a young mother with no family history of note.

\section{Medical and pregnancy histories}

Patients were carefully questioned about their general health and about the early days of their pregnancy, with particular reference to medication, pyrexial illness, radiography, or other relevant features. Of 47 patients who gave this information, three could recall taking medication at a time relevant to the phase of neural tube closure. One was still taking the contraceptive pill, one an unidentified antibiotic and analgesic (Novalgin) because of a tooth abscess, and the third had been given three different antihistamines because of a widespread allergic rash of unknown cause. No other significant features were elicited from the patients' histories.

\section{Potato-eating habits}

In Turkey bread is the staple diet eaten at all meals,

Table 1 Neural tube defects according to year and hospital, with incidence rates, Izmir 1974-76

\begin{tabular}{|c|c|c|c|c|c|c|c|c|c|}
\hline \multirow[b]{2}{*}{ Hospital } & \multicolumn{3}{|c|}{1974} & \multicolumn{3}{|c|}{1975} & \multicolumn{3}{|c|}{1976} \\
\hline & $\begin{array}{l}\text { Total } \\
\text { births }\end{array}$ & $\begin{array}{l}\text { Anen- } \\
\text { cephaly }\end{array}$ & $\begin{array}{l}\text { Spina } \\
\text { bifida }\end{array}$ & $\begin{array}{l}\text { Total } \\
\text { births }\end{array}$ & $\begin{array}{l}\text { Anen- } \\
\text { cephaly }\end{array}$ & $\begin{array}{l}\text { Spina } \\
\text { bifida }\end{array}$ & $\begin{array}{l}\text { Total } \\
\text { births }\end{array}$ & $\begin{array}{l}\text { Anen- } \\
\text { cephaly }\end{array}$ & $\begin{array}{l}\text { Spina } \\
\text { bifida }\end{array}$ \\
\hline Tepecik Insurance & 6093 & 5 & 1 & 6576 & 8 & 4 & 7400 & 9 & 3 \\
\hline Eşref Paşa Council & 1480 & 2 & 0 & 1556 & 3 & 2 & 1576 & 1 & 0 \\
\hline Izmir State & 3766 & 10 & 1 & 3679 & 9 & 3 & 3442 & 17 & 7 \\
\hline Karşiyaka State & 409 & 0 & 0 & 341 & 0 & 1 & 580 & 0 & $\mathbf{0}$ \\
\hline Railway Workers' & - & - & - & 66 & 1 & 0 & - & - & - \\
\hline Ege University & 2260 & 6 & 0 & 2601 & 8 & 1 & 2950 & 10 & 1 \\
\hline Total & 14008 & 23 & 2 & 14819 & 29 & 11 & 15948 & 37 & 11 \\
\hline
\end{tabular}

Rate per 1000 births-Anencephaly : 1.99 
with additional bulk provided by rice, macaroni, or a cracked wheat-seed product known as bulgur. Patients were questioned about how frequently they used potatoes in their diet to see if there was any correlation between regular potato-eating and anencephaly in this population. Four or more times a week was recorded as regular eating, two or three times moderate, once a week or two weeks rare, less than this, and those who never ate potatoes, constituted a fourth group.

Table 2 shows that the potato consumption of mothers bearing ASB infants is somewhat less than that of the control group of mothers bearing healthy infants.

Table 2 Neural tube defects according to potato-eating habits of mothers, Izmir 1974-76

\begin{tabular}{lccc}
\hline Potato-eating habit & $\begin{array}{l}\text { No. of } \\
\text { patients }\end{array}$ & $\%$ & \% control \\
\hline Regular & 1 & 2.0 & 3.4 \\
Moderate & 10 & 19.5 & 40.3 \\
Rare & 32 & 62.5 & 54.6 \\
Very rare or nil & 8 & 16.0 & 1.7 \\
\hline
\end{tabular}

\section{Water}

In the United Kingdom there is conflicting evidence on the relevance of water hardness to aetiology, (Fedrick, 1970; Fielding and Smithells, 1971). The water supply to the city of Izmir has a moderate calcium content, 80 parts per million. The adjacent town, in which the university is situated, has a separate supply with a content of $134 \mathrm{ppm}$, but the incidence of anencephaly there did not differ significantly from that in the city itself. Of patients coming from provincial villages, 12 came from villages with soft water and three from villages with hard water.

Other mineral factors such as aluminium, barium, and copper were not evaluated (Morton et al., 1976).

\section{Other factors}

The findings in relation to age and parity (Edwards, 1958) and socioeconomic grouping (Anderson et al., 1958) broadly confirm many previous surveys.

$A$ raised incidence of CNS abnormalities and spontaneous abortion in sibling pregnancies and a more frequent family history of abortion again corroborated earlier findings (Record and McKeown, 1950; Carter et al., 1967).

In this area it was noteworthy that $13.5 \%$ of the index ASB pregnancies were immediately preceded by a medical termination of pregnancy. It is impossible to define the abortion rate, but it is much lower than this figure.
Consanguinity was noted in two families of 58 patients questioned. In both cases, husband and wife were first cousins.

\section{Discussion}

The main purpose of this study was to provide a set of data on the epidemiology of ASB in a Near East area for reference and comparison. The only previous report was a brief summary from the University of Shiraz in Iran (Damyanov, 1971). For this reason, the collected data have been reported in some detail even though these mainly corroborate similar data collected in other parts of the world.

The incidence of anencephaly is high compared with the Shiraz study and distinctly high in comparison with that in India and South-east Asia. It compares more closely with the Balkan area (Czeizel and Revesz, 1970) than with the area of ethnic origin of the Turks, central and north-east Asia. In western Turkey the influence of peoples from the old Ottoman Empire stretching through the Balkans into Europe may be significant. It is noteworthy thato immigrants from the West, mainly Yugoslavia, are disproportionately represented in the mothers of anencephalics. A similar study in central or easterni Turkey would be of value to correlate with this.

The factor of potato consumption does not appea to play a significant role. The quantitative potato-eating habits of the population should have led to a low incidence of ASB if this factor had beef important. However, even more relevant is the fact that phytothora infestans is extremely rare in Turkey and virtually unknown in the Aegean region where this study took place (Internal Report, 1972). There was no correlation between the potato-eating habits and the ethnic background of the patients or their relatives.

The twin material raises some important issues in relation to the aetiology of anencephaly. Table 3 adds the material from this study and from an unpublished study by one of the authors to several other consecutive studies of ASB where twin data has been noted. Only the series in which there is explicit evidence of zygosity have been included. True concordance indicates the identical neural tube anomaly; ASB concordance includes cases where one member is anencephalic and the other spina bifida. Several large collections of ASB twin material have been analysed using the Weinberg assumption to determine the number of $M Z$ twinnings represented by the series. That of Rogers and Weatherall (1976) demonstrated a concordance rate of $6.4 \%$ in like-sexed twins and $1.6 \%$ in unlike-sexed twins. However, if a sex-related feto-fetal interaction as suggested by Knox (1974) underlies the 
Table 3 Consecutive series of neural tube defects with explicit data on zygosity, related to concordance

\begin{tabular}{|c|c|c|c|c|c|c|c|c|c|c|c|}
\hline \multirow[b]{3}{*}{ Series } & \multirow{3}{*}{$\begin{array}{l}\text { Total no. } \\
\text { of } \\
\text { cases }\end{array}$} & \multirow{3}{*}{$\begin{array}{l}\text { ASB } \\
\text { twin } \\
\text { pairs }\end{array}$} & \multirow[b]{3}{*}{$M Z$} & \multirow[b]{3}{*}{$D Z$} & \multirow{3}{*}{$\begin{array}{l}\text { Zygosity } \\
\text { unknown }\end{array}$} & \multicolumn{6}{|c|}{ Concordance } \\
\hline & & & & & & \multicolumn{2}{|c|}{ Mixed ASB } & \multicolumn{2}{|c|}{ Spina bifida } & \multicolumn{2}{|c|}{ Anencephaly } \\
\hline & & & & & & $M Z$ & $D Z$ & $M Z$ & $D Z$ & $M Z$ & $D Z$ \\
\hline $\begin{array}{l}\text { Field and Kerr (1974) } \\
\text { Smithells et al. (1964) }\end{array}$ & 1560 & 35 & 14 & 18 & $\mathbf{0}$ & 1 & 1 & 2 & 0 & $\mathbf{0}$ & $\mathbf{0}$ \\
\hline Smithells and Chinn (1965) & 438 & 7 & 1 & 5 & 1 & 1 & 0 & $\mathbf{0}$ & 0 & 0 & $\mathbf{0}$ \\
\hline Dumoulin and Gordon (1959) & 53 & 4 & 1 & 3 & $\mathbf{0}$ & 0 & 0 & 0 & 0 & 0 & $\mathbf{0}$ \\
\hline St. Catherines Hospital $\dagger$ & 76 & 1 & 1 & $\mathbf{0}$ & 0 & 0 & $\mathbf{0}$ & 0 & 0 & 1 & $\mathbf{0}$ \\
\hline Izmir Hospitals & 113 & 2 & 1 & 1 & 0 & 1 & 0 & $\mathbf{0}$ & $\mathbf{0}$ & 0 & 0 \\
\hline Total & 2240 & 49 & 18 & 27 & 1 & 3 & 1 & 2 & 0 & 1 & 0 \\
\hline $\begin{aligned} \text { ASB concordance- }-\mathrm{MZ} & =\% / 18 \\
-\mathrm{DZ} & =1 / 27 \\
\text { True concordance- }-\mathrm{MZ} & =\% 11 \\
-\mathrm{DZ} & =\% / 27\end{aligned}$ & $\begin{array}{l}=33.3 \% \\
=3.7 \% \\
=16.7 \% \\
=0.0 \%\end{array}$ & & & & & & & & & & \\
\hline
\end{tabular}

† Unpublished series by one of the authors

occurrence of ASB, then the rate of concordance in unlike-sexed twins would tend to be reduced. This would make predictions based on sex patterns in twins unreliable. This series confirms the findings in the only significant collection of twin data from a consecutive series where clear evidence of zygosity was available (Field and Kerr, 1974). It suggests, however, that true concordance occurs overwhelmingly in MZ twinnings and that even ASB concordance occurs in $\mathrm{MZ}$ pregnancies at a rate significantly higher than that in DZ pairs. The ASB concordance rate in $\mathrm{DZ}$ twins is compatible with the theoretically expected sibling rate of $4 \%$ to $5 \%$.

Although cases of true concordance occur predominantly in $\mathrm{MZ}$ twinnings, the rarity of the occurrence of true concordance is still the striking feature in relation to the genetic component in aetiology (Yen and McMahon, 1968).

One of the predictions of Knox's hypothesis (1974), the association with maternal age, was tested on Canadian data by Elwood (1976) and found to be not confirmed. The prediction of a variation in sex distribution of immediately preceding siblings is tested here on a limited sample. The variation predicted by Knox's theory is not sustained in 25 cases where data were available (Table 4). The data on sex ratio in relation to social class were not complete in classes I and II, so were not valid in interpreting the Knox prediction. However, the large

Table 4 Sex ratios in immediately preceding sibs in relation to Knox's prediction

\begin{tabular}{lcl}
\hline M/F ratio & Male propositi & Female propositi \\
\hline Knox prediction & $2: 1$ & $5: 1$ to $9: 1$ \\
$\begin{array}{l}\text { Record and McKeown } \\
(1950)\end{array}$ & $1 \cdot 1: 1$ & $1.6: 1$ \\
Izmir & $1 \cdot 1: 1$ & $1.3: 1$ \\
\hline
\end{tabular}

secular variation in sex ratio over the three years (Fig. 2) is striking, and although spina bifida data for 1974 are incomplete, there is no reason to suspect that that should significantly disturb the extraordinary female preponderance in that year. This exceptionally low male/female ratio in the year of relatively low incidence of ASB is contrary to Knox's prediction.

Although this study provides some interesting pointers in cautioning against a too ready acceptance of Knox's attractive theory, the data are limited and further testing is needed against more substantial material.

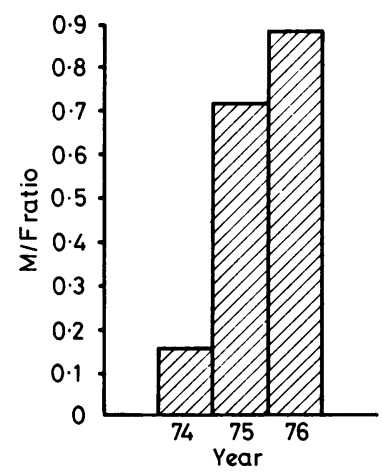

Fig. 2 Neural tube defects: sex ratios according to year of birth, Izmir, 1974-76.

We would like to record our appreciation of the help given to us by the late Professor Muvaffak Arican. We thank the staffs in all the Izmir hospitals, and Mrs. Bennett.

Reprints from Dr. Mike Buckley, Elim Krankenhaus, Hamburg 19, West Germany. 


\section{References}

Anderson, W. J. R. (1958). Epidemiology of still births and infant deaths due to congenital malformation. Lancet, 1 , 1304-1306.

Carter, C. O., Laurence, K. M., and David, R. A. (1967). The genetics of the major central nervous system malformations based on the South Wales socio-genetic investigation. Developmental Medicine and Child Neurology, 9, 30-34.

Czeizel, A., and Revesz, C. (1970). Major malformations of the central nervous system in Hungary. British Journal of Preventive and Social Medicine, 24, 205-222.

Damyanov, I., and Dutz, W. (1971). Anencephaly in Shiraz, Iran. Lancet, 1, 82.

Dumoulin, J. G., and Gordon, M.E. (1959). Anencephaly in twins. Journal of Obstetrics and Gynaecology of the British Empire, 66, 964-968.

British Medical Journal (1976). Editorial: Epidemiology of anencephalus, spina bifida and congenital hydrocephalus. British Medical Journal, 2, 1156.

Edwards, J. H. (1958). Congenital malformations of the central nervous system in Scotland. British Journal of Preventive and Social Medicine, 12, 115-130.

Elwood, J. M. (1976). Twinning and anencephalus occurrence in relation to fetus-fetus interaction. British Journal of Preventive and Social Medicine, 30, 29-31.

Fedrick, J. (1970). Anencephalus and the local water supply. Nature Lond.) 227, 176-177.

Field, B., and Kerr, C. (1974). Twinnings and neural-tube defects. Lancet, 2, 964-965.

Fielding, D. W., and Smithells, R. W. (1971). Anencephalus and water hardness in south-west Lancashire. British Journal of Preventive and Social Medicine, 25, 217-219.
Internal Report (1972). Phytothora infestans in Turkey. The International Potato Centre, Region IV. Menemen: Turkey.

Knox, E. G. (1974). Twins and neural tube defects. British Journal of Preventive and Social Medicine, 28, 73-77.

Morton, M. S., Elwood, P. C., and Abernethy, M. (1976). Trace elements in water and congenital malformations of the central nervous system in South Wales. British Journal of Preventive and Social Medicine, 30, 36-39.

Nance, W. E. (1971). Anencephaly and spina bifida, an aetiologic hypothesis. Birth Defects, 7 (1), 97-102.

Record, R. G., and McKeown, T. (1949). Congenital malformations of the central nervous system. British Journal of Preventive and Social Medicine, 3, 183-219.

Record, R. G., and McKeown, T. (1950). Congenital malformations of the central nervous system III. Risk of malformation in sibs of malformed individuals. British Journal of Preventive and Social Medicine, 4, 217-220.

Record, R. G. and McKeown, T. (1961). Anencephalus in Scotland. British Journal of Preventive and Social Medicine, 15, 93-105.

Rogers, S. C., and Weatherall, J. A. C. (1976). Anencephalus, spina bifida, twins and teratoma. British Journal of Preventive and Social Medicine, 30, 26-28.

Smithells, R. W., Chinn, E. R., and Franklin, D. (1964) Anencephaly in Liverpool. Developmental Medicine and Child Neurology, 6, 231-240.

Smithells, R. W., and Chinn, E. R. (1965). Spina bifida in Liverpool. Developmental Medicine and Child Neurology, 7, 258-268.

Yen, S., and McMahon, B. (1968). Genetics of anencephaly and spina bifida, Lancet, 2, 623-626. 